\title{
Bioenergy II: production of biodegradable lubricant from Jatropha curcas and trimethylolpropane
}

\begin{abstract}
Jatropha oil has good potential as the renewable energy as well as lubricant feedstock. Production of Jatropha oil based lubricant was performed via a two-step process; (i) the transesterification of Jatropha oil to produce Jatropha Methyl Ester (JME) and, (ii) transesterification of JME with trimethylolpropane (TMP) under the presence of alkaline based catalyst. Transesterification of Jatropha oil was carried out at $65^{\circ} \mathrm{C}$ for 1 hour by using $1-2 \% \mathrm{NaOH}$ as catalyst. While, the transesterification of JME was carried out at $150^{\circ} \mathrm{C}$ with pressure kept at 10mbar. The conversion of JME to jatropha biolubricant was found to be more than $80 \%$. However, to maintain forward reaction, the amount of JME was maintained at about 4:1 ratios to TMP. The basic properties of jatropha biolubricant are found comparable to other plant based biolubricant.
\end{abstract}

Keyword: Trimethylolpropane; Jatropha curcas; Biodegradable lubricant 